\title{
The Dawn of Rational Intersubjectivity in Hegel's Philosophy of Subjective Spirit
}

\author{
Charis Stampoulis \\ Department of Philosophy and Education, Aristotle University of Thessaloniki, Thessaloniki, Greece \\ Email: chstamp@edlit.auth.gr
}

How to cite this paper: Stampoulis, C. (2020). The Dawn of Rational Intersubjectivity in Hegel's Philosophy of Subjective Spirit. Open Journal of Philosophy, 10, 300-315.

https://doi.org/10.4236/ojpp.2020.103020

Received: March 29, 2020

Accepted: July 3, 2020

Published: July 6, 2020

Copyright $\odot 2020$ by author(s) and Scientific Research Publishing Inc. This work is licensed under the Creative Commons Attribution International License (CC BY 4.0).

http://creativecommons.org/licenses/by/4.0/

\begin{abstract}
This article aims to explore the Hegelian views on humanity's emancipation from the natural condition and the gradual process of social rationalization. In the context of an immanent determinative movement from abstract to concrete, the dialectical process passes through the concepts of natural spirit, consciousness and self-consciousness, until the concept of rational spirit becomes its terminal station. Given that Hegel himself locates the prelude to the right-oriented or just relation already in the rational mutual recognition of the particular self-consciousnesses, i.e. at the terminal point of a dialectical deduction that starts from the concept of natural spirit and moves through the concepts of consciousness and self-consciousness, this article tries to reconstruct in broad lines the key points of this process. According to Hegel, the total transit through all these three evolutionary stages is crowned by the ability of spirit to come to terms with the objective completion of its concept, that is to think of itself not only as a subjective structure, opposite to an external object, but as homogenous to objectivity, in the meaning of the thing itself (die Sache selbst). The moment of rational intersubjectivity is of cardinal importance for this completion, which grants spirit the ability for intelligent theorizing and just practical conduct.
\end{abstract}

\section{Keywords}

Social Philosophy, Political Philosophy, Hegel, German Idealism

\section{Introduction}

How do we, the naturally borne beings, come to organize our co-existence on the basis of universally recognized rules? In which-actually unexpected-way, through the dense darkness of bestial unconsciousness, rises the sun of conscious moral responsibility, the terrain of compulsory mutual accountability and 
ultimately, the world of the legally regulated relationship? For Hegel, the answer to this question is intertwined with a complex dialectical deduction of the concepts of reason and free will.

The exposition of the generative process of the concept of reason takes place, with regard to the general map of the Hegelian philosophical system, in the Philosophy of Spirit (Hegel, 2007), found mainly in the section called Subjective Spirit. In the context of an immanent determinative movement from abstract to concrete, the dialectical process passes through the concepts of natural spirit, consciousness and self-consciousness, until the concept of rational spirit becomes its terminal station ${ }^{2}$ (Houlgate, 2006; Winfield, 2012). The inherent determinative transmutation of the latter into the concept of free will marks the systematic transition from the territory of the subjective spirit into the zone of the objective spirit. At this point, natural spirituality has finally collected within its conceptual circle the concrete totality of conditions that will allow for its complete conversion into a kind of second, self-regulated nature, i.e. into a relation of right.

It goes without saying that it is impossible to make an exhaustive theoretical reconstruction of the overall deductive process of the concept of objective spirit, which opens up the realm of free and just conduct. Actually, this realm is theoretically established through the entire development of subjective spirit, that is always determined by elements of natural, anthropological and psychological origin; these elements being the real conditions of possibility for the inaugural concept of right i.e. free will, while being sustained within the latter as sublated, in accordance with the dialectical meaning of the term "sublation" (Aufhebung) ${ }^{3}$ (Burbidge, 2007). However, such a lengthy project would have been impossible to implement without breaking the limitations of this article, as to its permissible extent $^{4}$ (Winfield, 2011). Consequently, given that Hegel himself locates the prelude to the right-oriented or just relation already in the rational mutual recognition of the particular self-consciousnesses, i.e. at the terminal point of a dialectical deduction, that starts from the concept of natural spirit and moves through the concepts of consciousness and self-consciousness, I will try to reconstruct in broad lines the key points of this process, leaving aside the task to explicate the content of the concept "reason", which opens up the epistemic field of Hegelian psychology and effects the final transition to the concept of free will, the inaugural concept of the Philosophy of Right.

${ }^{1}$ G. W. F. Hegel, Philosophy of Mind (New York: Oxford University Press, 2007), 3-215.

${ }^{2}$ For coherent reconstructions of the Hegelian dialectical method and its process of movement from one conceptual content to the other see, among others: Stephen Houlgate, The Opening of Hegels Logic (West Lafayette, Indiana: Purdue University Press, 2006), 32-54 and Richard Dien Winfield, Hegel s Science of Logic (Plymouth, UK: Rowman \& Littlefield Publishers, 2012), 345-357.

${ }^{3}$ For important insights on the concept of Aufhebung see: John W. Burbidge, Hegels Systematic Contigency (New York: Palgrave Macmillan, 2007), 91-92.

${ }^{4} \mathrm{~A}$ thorough exposition and complete overview of Hegel's conceptual realm of subjective spirit is contained in Richard Dien Winfield, The Living Mind (Plymouth, UK: The Rowman \& Littlefield Publishers, 2011). 


\section{The General Structure of Subjective Spirit}

The concept of subjective spirit is firstly presented as immediate, namely, in the determination of abstract universality. Its immediacy is due to the fact that its entity is a descendant of the sublation of mediation (Vermittlung) ${ }^{5}$ (Sparby, 2015), through which its emergence from the realm of nature takes place. Owing to this immediacy, the entity of the spirit is stated as given and not yet as self-generated. This "givenness" is made manifest in the immediacy of the relation of spirit to its natural and spiritual characteristics. Because of this immediacy, spirit bears the character of natural spirit, or alternatively, of soul. Its evolutionary progress consists in overcoming the direct intermingling with the natural factor and reducing the latter to a "sign" of mental life.

Secondly, subjective spirit appears as mediated. In this moment (Moment) of its overall determination, the universality (Allgemeinheit) of its concept proceeds to its particularization (Besonderung). As we now know from Logic (Hegel, 2010), the particularization of universality lies in its division between itself and particularity. So, the spirit in this case manifests itself as a reflexion (Reflexion) ${ }^{7}$ (Burbidge, 1981) in itself as into the other of itself. The other is the equivalent of the sublated and reduced to a "sign" physicality; a sublation which, on the one hand, emancipates natural spirit from its immediacy by granting it a distinctive independence against an otherness and so generating its ability to be conscious of something in general. However, on the other hand, it embeds it in a relation of dependence on the object of its consciousness. This object is also presented as something independent, to which consciousness, in the shape of representation, refers in order to fill its formal self-reference with content. In this dual interconnection the primacy of spirit seems to be secured by the fact that in the concept of consciousness the concept of a determinate other is already included.

Thirdly, subjective spirit, in the conceptual determination of individuality (Einzelheit), addresses the very constituent nature of its formal self-determination. Individuality makes the universality of self-determination concrete as it engenders its unification with particularity, while sublating the apparent independence of the moment of oppositional referentiality that has to do with consciousness. This is initially the case when inside the realm of mediation consciousness is transformed into self-consciousness, objectifying its own consciousness-defined differentiality. The further restoration of spiritual universality coincides with the individualized reason, unified and indivisible in its diversity.

The total transit through all these three evolutionary stages is crowned by the ability of spirit to come to terms with the objective completion of its concept, that is to think of itself not only as a subjective structure, opposite to an external

${ }^{5}$ The crucial role of Vermittlung in Hegel's speculative dialectical method is well explained in TerjeSparby, Hegels Conception of the Determinate Negation (Leiden, The Netherlands: Brill, 2015), 314-340

${ }^{6}$ G. W. F. Hegel, The Science of Logic (New York: Cambridge University Press, 2010), 530-546.

${ }^{7}$ For the Hegelian concept of Reflexion see John Burbidge, On Hegel s Logic, (Atlantic Highlands, US: Humanities Press, 1981), 61-83. 
object, but as homogenous to objectivity, in the meaning of the thing itself (die Sache selbst). Just as in the Science of Logic the subjective concept initially substantiates itself in an entirely ideal manner and subsequently in a way that is real, namely as judgment and syllogism, in order to arrive at its objective being, in the Philosophy of Spirit, the concrete spiritual structure, an organic composition of universality, particularity and individuality proceeds to the retrospective foundation $^{8}$ (Rockmore, 1986) of the objectivity of its autonomous nature. Retrospective foundation means for sure that the substance of autonomy is, as it ought to be, a product of self-creation and by way of this, not a reflection of an immediate libertarian principle, either empirical and finite, as most theorists of modern natural right assume, or absolute, but in an immediate and given fashion, in accordance with the higher Kantian perspective.

\section{Natural Spirit}

Thus, in its primary emergence, the spiritual element takes on the character of soul or natural spirit. Under the determination of natural soul Hegel subsumes the investigation of the natural spiritual qualities and the feeling soul. Under the determination of the feeling soul, the dialectical process is divided into the moments of feeling soul, self-feeling soul and habit.

Natural spirit reflects the primary spiritualization of nature, in the sense that the immediate connection to the corporeality is now no more accounted for as being-out-of-oneself, namely as sheer naturalness. On the contrary, self-determination and individual corporeality flow together in a simple concrete unity. However, the fact that the universality of self-determination has not yet managed to be filled with content in a self-active way causes its inevitable inclination either to the side of immediate corporeality or to that of immediate mentality, unaware of the inherent contrast between them. Hence its identification with the sleeping spirit and the passive mind of Aristotle, which is potentially everything. This potentiality is synonymous with a primordial indifference, as long as the form and the content belong together in an indiscriminate unity and the divergence between them has not yet been manifestly posited as such. Instead it remains submerged into an unconscious co-existence. Again, the passivity is due to the fact that spirit resides immediately in the aforementioned unity, before the latter develops into a derivative moment of a process of subjectification. It is to be immanently demonstrated that the initial spark for the process of subjectification to unfold is given by the emergence of a still undeveloped kind of relation, by virtue of which the undifferentiated identification with the physicality is transformed into a relationship of the feeling soul to the body. This is an evidently primordial and immature form of association, precisely because the determination of immediate unity remains dominant and does not allow the determination of opposition to arise.

${ }^{8} \mathrm{~A}$ comprehensive deciphering of Hegel's retrospective and circular foundation of conceptual truth is contained in Tom Rockmore, Hegel s Circular Epistemology (US: Indiana University Press, 1986), $1-110$. 
Initially, the sleeping self-determination of natural spirit is endemic to the element of inactive universality. Self-differentiation remains undone; as a result spirit appears to be an inert substance without ownership of its contents. Therefore, these contents seem to pertain to spirit under the guise of given natural qualities. Examples of such qualities are the movement of the universe, climatic differences, periods of the year and day etc. Naturally, these are universal determinations, which pertain to spiritual life as such, in the immediacy of its concept, regardless of its further differentiations. The latter, in this case, are still natural qualities. Here belong the geographical and racial divisions of immediate universal spirituality, with all the accidentalities of the special locality and physical temporality; additionally, anthropological characteristics such as temperament, talent, character, physiognomy etc.

The progressive resurgence of the ideality of spirit in the present context is mediated by the awakening of feeling. The feeling spirit is able to break away from the immediate givenness of its qualitative determinations, variations and modifications, recognizing them as symptoms of its own self. Nevertheless, the feeling subjectivity remains formalistic, insofar as it has not risen to the objectivity of its concept, so as to stand as a conscious independence against the independence of the object. The mediating term that performs the connection of self-determined spirituality with itself here consists of an accidental subjectivity, attached to the hic et nunc of its sensory data and is therefore essentially alien to the self-determined spirituality. Owing to this imperfect connection, the form and content of spirit, the subjective and objective self-determination stay in difference. The conceptual movement that sublates this difference runs through the evolutionary stages of self-feeling spirituality and of spirituality which is capable of habitual activity.

Remarkable progress towards freedom marks the spiritual structure of habit (Gewohnheit). Habit is claimed to be the ultimate conceptual stage before spirit arises as consciousness. Although in the determination of habit natural spirit is not yet informed by the "I" of consciousness, habit is characterized by Hegel as the foundation (Grundlage) of the latter. Its emergence is tantamount to a decisive sublation of the immediate self-subsistence of particular sentimentality and corporeality. In the conceptual frame of habit, the body and the emotions are reduced to pure ideality and are subsumed to the determination of pure Being, that is to the abstract universality of the concept. Therefore, the self-determined spirit comes by virtue of habit in relation, not to this or that particular physical element and passion of its own, but rather to the abstract unity of its immediate instantiations and as long as the abstraction is necessarily carried out mentally to the being-for-itself of its concept.

Consequently, habit marks a stage of spiritual evolution in which the form of freedom manages, largely, to restore its contents to the immanence of its conceptual self-development. The exercise of control over the conceptualized mental and corporeal contents allows natural spirit, actually still in an unconscious manner, to move within their territory and to actively identify or unidentify it- 
self with some or other of them, without surrender to the delusion of their unmediated givenness. The sovereignty of spirit over the contents of its habitual identifications conveys itself in the form of practical repeatability, which constitutes an embryonic stage of absolute spiritual self-generation. Consequently, the unmediated unity with the multiplicity of physical, corporeal and sensual determination is transformed into a posited unity. However, on the horizon of this posited unity, the difference between the determining and the determined remains for sure ineliminable.

In the current spiritual stage, the subjective side of habit is subscribed to the determination of an incomplete and abstract universality, which determines but does not produce the ultimate individuality of its contents. It just reproduces externally given data, that support the continuation of its determining role and on which spirit is reflected as if upon a mirror, that makes its positing activity manifest. Therefore, spiritual emancipation from the natural factor is still deficient. The repeatability of habit takes on mechanistic characteristics and utters autonomy in terms of necessity. That is why habit is reasonably characterized by Hegel, echoing Aristotle, as second nature.

The second nature of habit takes over the entire territory of immediate spirituality and exercises its influence almost onto the completely elementary functions of the body and soul. Their random individuality is absorbed into a universal programmatic framework of operation that reconstructs them as an action of the positing spiritual subjectivity. The innocent and infantile reconciliation with the natural corporeality becomes a relationship of disciplined education, to the extent that the body is motivated to develop skills and to coordinate the multiplicity of its activity in a single frame of reference. So it also becomes a participant in the self-realization of spiritual autonomy.

In terms of habit, the partial rise of the spiritual self to its free subjectivity is actualized by the transfiguration of corporeality into a "sign" (Zeichen) of the spiritual ideality. The corporeal determinate-being and spirituality come together in unity, which is not in fact neutral because the emphasis falls onto the side of spiritual self-actualization, as the self-contained, the negative and the nonpregiven term of the connection.

The reduction of the natural circle to a determinate totality, i.e. to something mental, marks its entrance into the determination of the object that stands over and against a subject. Objectivity and subjectivity emerge and oppose each other. When spirit refers to an objective, independent external world as the enemy of its own independence, it ceases to be merely natural spirit and ascends to consciousness (Bewusstsein).

\section{Consciousness}

The moments of self-relation and distinctive separation permeate the fundamental referential structure of consciousness. In the otherness, the self is to be intuited and the self is to be intuited in the otherness. The independence of the other, its transformation into a self-contained objectivity contributes to the ob- 
jective consolidation of subjectivity. Conversely, the objectivity of the object is canceled without its reference to the subject. Spirit conceives its independence from the other as a certainty of its own being, in the sense that the objectivity of the other constitutes a function of its own act of objectification. “... I is one side of the relationship and the whole relationship-the light which reveals itself and an Other too", says Hegel ${ }^{9}$ (Hegel, 2007). And expanding this iconographic explanation he writes: "Just as light is the manifestation of itself and its Other, darkness, and can reveal itself only by revealing that other, so too the I is revealed to itself only in so far as its Other becomes revealed to it in the shape of something independent of it" ${ }^{10}$ (Hegel, 2007). However, the expression that the I is both the one side of the relation and the total relation points out precisely the fact that the element of immediate self-certainty has not yet been elevated to an explicit and proven truth.

Consciousness, on the one hand, starkly separates its formal universality from the otherness, leaving the element of distinctive differentiation within the jurisdiction of the latter. However, at the same time as long as consciousness, according to its concept, is something self-determined, it continues to preserve differentiality within itself. Divided into consciousness and objectivity, differentiality operates as a middle term, so that spirit and its other come into a relation that is translated into the referentiality of consciousness. Inasmuch as the element of differentiation also reveals its egological origin, the relation to other will continue to be subscribed to the horizon of self-relation, being one among its positing operations.

At the same time, the objective other of consciousness includes all its previous evolutionary steps. The contradiction of consciousness lies in the fact that the relation of opposition to its repelled naturalness is identical to a relation of inclusion. The independence of both sides and its sublation in the identity of the I, the coexistence of immediate otherness and selfness within a single frame of reference, inserts consciousness within the sphere of appearance. That is, the absolute negativity ${ }^{11}$ (Bowman, 2013) of the self-constituting spiritual unity appears to be refracted; a disunited difference between its identifying and differentiating sides seems to take the lead. Nevertheless, absolute spiritual negativity denotes the disengagement from the external givenness of determinative difference. However, the dialectical movement through all the moments of the duality of consciousness will be necessary in order to fully obtain this disengagement.

One symptom of the apparent givenness that affects the performance of the spiritual self-determination is the appearance of I's self-enacted differentiation as something performed by the object. The determinations of free self-constitution present themselves as having been caused by an external source of determination. Thus, the posited determinations appear as beings. "The goal of mind, ${ }^{9}$ G. W. F. Hegel, Philosophy of Mind (New York: Oxford University Press, 2007), 142 (\$413). ${ }^{10}$ G. W. F. Hegel, Philosophy of Mind (New York: Oxford University Press, 2007), 143 (\$413, Zusatz). ${ }^{11}$ Brady Bowman provides an elaborate explication of the concept of "absolute negativity" and stresses its cardinal importance for the Hegelian dialectics in his Hegel and the Metaphysics of Absolute Negativity (New York: Cambridge University Press, 2013). 
as consciousness, is to make its appearance (Erscheinung) identical with its essence, to raise the certainty of itself to truth"12 (Hegel, 2007). From the point of view of the relationship between form and content the problem of consciousness is reduced to the fact that consciousness, metaphorically speaking, affirms itself as the typical owner of its content, a property title, however, without objective fulfillment, insofar as the specific aspects of the content remain outside the determining operativeness of consciousness. The owned is indifferent to the established "property relationship" and the latter is unable to promote identity with the object beyond the region of a subjective postulate.

The dialectical process that specifies the modifications of the differentiality of consciousness and the retrospective sublation of difference moves through the concepts of consciousness and self-consciousness, to culminate in the concept of reason. The terminal station represents the differential unity of consciousness and self-consciousness. To begin with, the object, resounding Fichte, is equated with the non-I, and the self-reference of consciousness within the object is in parallel to a progressive internalization and subjectification of the non-I itself. Therefore, there are two opposing but converging movements; one of subject's objectification and one of object's subjectification. Only when the objective arrives by its own means to the determination of subjectivity will the subject become aware of the objective character of its determinative activity. At that point, the conscious I becomes capable of being reflected in itself as objective I. The differentiality of consciousness thus becomes the object of consciousness and in this way consciousness is transformed into self-consciousness.

\section{Self-Consciousness and the Battle of Recognition of Self-Consciousnesses}

The encapsulation of the difference of consciousness between I and non-I renders self-consciousness self-differentiating. Due to the restored objectivity of self-determination, this self-differentiation manifests itself in the form of self-repulsion, because the self-determining in general does not have an immediate self, but a self posited in its immediacy. The repelled immediate self of self-consciousness is placed into another self-consciousness structurally identical and at the same time independent of the former, as objectively free. Therefore, the universality of self-consciousness, insomuch as it includes the element of the referentiality of consciousness, is converted into a relation between self-consciousnesses. The field for the relation of mutual recognition (Anerkennung) is wide open $^{13}$ (Peperzak, 2001; Fichte, 2000).

${ }^{12}$ G. W. F. Hegel, Philosophy of Mind (New York: Oxford University Press, 2007), 145 (\$416).

${ }^{13}$ Adriaan Peperzak stresses successfully the hermeneutical dangers contained in the overestimation of the concept of Anerkennung and its supposed role as a magic key to be used in order to account for all the complications of Hegel's practical philosophy: Adriaan Peperzak, Modern Freedom: Hegels Legal, Moral and Political Philosophy (Dordrecht, The Netherlands: Kluwer Academic Publishers, 2001), 141. Nevertheless, it is of major importance to indicate the Fichtean root of the concept of mutual recognition of rational beings in his Foundations of Natural Right (New York: Cambridge University Press, 2000), 29-79. 
According to the Encyclopedia of 1830, the intellectual conception of the internal law of the phenomenon is a turning point for the subjectification of the object and the subsequent evolution of consciousness into self-consciousness. In contrast to the character of sensed and perceived objectivity, the intellectual objectivity of the law predicates difference to a pure framework of internality and ideality. In particular, the immediate entity of a sensed individuality, immersed in space and time, relates to itself as something self-external. Accordingly, the object of perception is always mediated by another, so as never to be able to possess its self-subsistence irrespective of relation. As subsumed under an intellectually formed law, in contrast, the object of consciousness is promoted in terms of ideality, because it retains its distinctions as internal modifications within the whole circle of its identity with itself. Such distinctions shall cease to be distinctions. Rather, they account for the constitution of the subjective and self-determining, i.e. that which maintains the integrity of itself in its differentiation. Therefore, intellectual consciousness determines the object in a way similar to the I.

Apart from the objectification of consciousness in the form of lawful universality, which underlies the accidental multiplicity of the sensed otherness, the object that comes to reflect even closer the ideality of consciousness and therefore, contributes decisively to the verification of consciousness's certainty of its spiritual autonomy, is the living organism. The multipartite structure of the organic being becomes directly conceivable as the appearance of an internal self-reference, correlative to the ideality of the natural law, but of a more active and energetic nature in comparison to that of the law. In addition, the exclusive individuality of the natural organism is not that of the immediately sensed, which is dispersed in the external other-relation, nor that of the perceived thing of properties, which has also been proven to be other-determined. On the contrary, it is conceived as a self-subsistent individuality relating to itself as an end in itself, inviting spirit to approach it solely for the sake of itself, i.e. regardless of its accidental relations to others. In the view of a living organism self-consciousness (Selbstbewusstsein) is ignited; for in the living creature the object is transfigured into subjectivity; this is where consciousness discovers itself as the essence of the object, turns to be reflected through the object into itself and becomes the object of its own self.

The rise of self-consciousness represents the birth of spiritual freedom, if indeed the more general definition of freedom indicates the non-limitation by something other and the discovery of the self into the actual otherness of the other. However, the risen self-consciousness is only immediately characterized by freedom, as if freedom were a given ontological definition of it and not the product of its own activity. But the very concept of freedom, as unconditional self-determination, requires precisely the latter. The initially conditioned being of self-conscious freedom lies specifically in the emergence of self-consciousness through the sublation of the endemic difference of consciousness, a sublation 
that is not yet revealed as a product of its own self-actualization. Therefore, self-consciousness comes into the contradictory state to stand for both the free and the conditional.

The defining frame of reference leading to contradiction is the opposition between consciousness, the difference between I and not-I, and self-consciousness, their identity. The contradiction emerges from the fact that each side includes its opposition to its definition. More precisely, the germ of self-consciousness within consciousness consists in the tendency of consciousness to verify the certainty of its freedom through the annulment of the object's externality. On the contrary, the germ of consciousness within self-consciousness consists of the very same tendency of verification, however this time by way of negating I's formal internality through the act of its own objectification. These two relationships are mutually determined, a fact that, while being tolerated on the part of consciousness, given that reference to otherness corresponds to its nature, it is encountered as a corrosive antinomy on the part of self-consciousness, given its unconditional character. Self-consciousness wants to determine itself unpresupposedly but self-determination is granted to it as a quasi-given, thanks to an unassimilated process of annulling the finite and demonstrating its phenomenal nature.

The removal of the residue of givenness in the self-determined spirit and the resolution of the contradiction are achieved by the subscription of the subjective and objective component of the opposition to a single act of self-relation, in order for the two reverse movements of emancipation, the first negative (identity as sublated difference), the second positive (identity as self-enacted differentiation), to be considered as one, with the result that the relationship between them may not be overdetermined in the manner of consciousness, but in the manner of self-consciousness. This process unfolds in parallel with a change in the object of self-consciousness. In particular, the latter gradually ceases to be defined by the relationship of self-consciousness to consciousness, thus by consciousness's context of determination, and begins to reflect the self-consciousness-oriented kind of relationship, namely the relationship of self-consciousness to its realization. Actually, the formal texture of self-consciousness has come to be amended: its immediately given form is shown to be something deduced by mediation of its own self-actualization.

This dialectical process is carried out and can be reconstructed by virtue of three consecutive keystones. In the first, self-consciousness manifests itself as desiring (begehrende Selbstbewusstsein), in the second as recognizing and recognized or as having undergone the process of recognition (Prozess des Anerkennens) and in the third, speculative integration of the previous two, as a concrete universal self-consciousness (allgemeine Selbstbewusstsein).

In particular, the perpetually renewed cycle of desire and satisfaction includes the negation of both the immediate individuality of the object and the immediate individuality of the subject, in such a way that both go into the determina- 
tion of universality. The individuality of the desired sublated by the subjectivity of satisfaction as to its immediacy and reconstituted returns back to itself as a unity of immediacy and mediation, that is to say, as universality. Whereas the entity of the desired was to be defined on the basis of an unlimited availability to the I, this definition is now sublated and the object acquires a compact and independent determination over against the subject. Concurrently, the individuality of subjective satisfaction, while having been negated in respect to its immediacy through the endless revival of desire, returns to itself as equally universal. Before an object of the same universality, the universality of the self-conscious spirit is objectively established in itself. Meaning, the positive independence that the desiring self-consciousness was looking for (and which was permanently frustrated, due to its reduction merely to a formal self-affirmation, dependent on the immediate cancellation of the object) now acquires, by virtue of the fact that the object is in a position to remain, a fixed determinate-being.

The universalization of subject and object induces the relationship of one self-consciousness versus another. The related terms maintain the unconditional universality of their freedom. At the same time, they stand as a separate particularity against another separate particularity, since they hold the moment of mediation within their respective universality. Their relation, as a whole, is so posited in the determination of particularity, which by definition is contrary to the non-subjected to conditions nature of freedom. As long as the related are equally free, the restoration of the non-conditioned nature of their relationship must emanate from the individual perspective of both. As a consequence, the emancipatory movement manifests itself dually, as a single process of mutual recognition of the free in their freedom.

The process of mutual recognition therefore, is spurred on by the radical contradiction between the universal unity of self-consciousness, the common essence of all spiritual beings, as Hegel characterizes it and its dispersion to opposite parts, which claim self-consciousness solely on their behalf. The disjointed selves maintain a self-founded, fixed and unshakeable determination against each other, suggesting that the process is not going to evolve smoothly and unfailingly, without resistance and competition. On the contrary, it bears the characteristics of contest and battle. The immediate independence of the other self-consciousness must be abolished, because whilst it exists, then the freedom of one self-consciousness, that is its ability to be continuous with itself in the other, is affected by the irreducible self-subsistence of the other.

The irreducible self-subsistence of both self-conscious subjects encloses each one in its immediacy. Such immediacy will take on the character of natural givenness in reference to the corporeality of each self-consciousness. Therefore, the abolition of the other's independence for the sake of my own freedom passes through the dissolution of his/her natural corporeality. Such dissolution, however, is not enough to be of a one-sided character and only concern the natural corporeality of the other. As long as natural givenness goes against self-determination, then my own corporeality must be undone too. The battle of recogni- 
tion triggers this two-sided risk of natural immediacy precisely for the sake of freedom. As a fighting self-consciousness I defy death, the major enemy of my physical immediacy, in order to assert the recognition of my freedom as something superior to my givenness. At the same time, I am endangering the other's corporeality with the aim, not only to destroy his independence, but also to stir his immanent subjectivity. Because only in this way can the risk of my natural being for the sake of freedom be recognized and elevated to the universality that freedom demands.

The by means of battle excitation of the other's freedom, namely the challenge so that he/she can defy his/her immediate biological life and rise to the self-conscious autonomy, indeed becomes the dominant dimension of the battle of recognition, although this battle is primarily motivated precisely by the seeking to remove this independent autonomy of the other. Ultimately, the purpose of the pursuers of freedom is neither the death of the one or the other. In fact, the total abolition of corporeality would not only be fatal to the determinate-being (Dasein) of freedom but also detrimental to the desired recognition, since the dead are neither free nor recognizing or being recognized. Consequently, freedom without determinate-being and without universal recognition would be the greatest of contradictions, states Hegel. For the battle of recognition is therefore sufficient to symbolically demonstrate the freedom of each competitor by virtue of risk and exposure to death. So the immediately opposed self-consciousnesses must ultimately submit themselves and their other to a symbolic death, even though in the course of the battle the possibility of natural death is always present. Each one's attitude to the eventuality of the threatening presence of natural extinction also determines the outcome of the fight. One of them usually turns out to be more fearless before death, more willing to safeguard its freedom at the risk of its life. The other, on the contrary, is completely overwhelmed by the terror of natural non-existence, preferring to sacrifice the recognition of its autonomy in order to preserve its life. Therefore, the first round of the battle of recognition results in the subjugation of one self-consciousness to the lordship of the other and the process of recognition turns out to be a relationship of domination and subjugation.

The springboard of the battle was the sublation of the particularity of self-consciousnesses. By the subjugation of the one particular self-consciousness to the other, the particularity is removed but only partially and unilaterally, because the subjugating, dominant self-consciousness keeps its specific particularity intact. However, freedom, according to its concept, requires the complete liberation from any specific foundational framework.

This release is initiated by the activity of the subordinate self-consciousness. Its subjugation is the result of the predilection for its immediate natural existence and the circle of its given desires at the expense of freedom. Nevertheless, through its subjugation to the domination of the other, the stream of its immediate desires is interrupted by the imperative word of that other. The master is the one to lead the relationship and direct the distribution of desire. Mainly, this 
happens by means of the working activity of the subordinate self-consciousness, given that productive work is necessary if both of them want to stay alive. However, the obligatory work of the subjugated self-consciousness contributes decisively to overcoming its immediacy. Because the worker suspends the unrestrained flow of his/her desire and subjects it to specific rationalization, depending on the task he/she has to accomplish each time. Moreover, his/her desire is not only private but also includes the desire of the other, thus extending to the horizon of universality. In this case, the other's desire is of course the desire of another immediate subjectivity, that of the lord. Therefore the proceeding rationalization is only instrumental, obeying hypothetical imperatives of prudence, as Kant would have said. Even so, the mere fact of discipline is conducive to the overcoming of the I's formal self-affirmation through the satisfaction of private desires and contributes to the voluntary self-actualization and self-formulation, which is the acquisition of the indispensable components of freedom.

The disciplined activity of the subordinate allows him/her to gradually obtain the emancipation from natural givenness; the emancipation that the master certified on behalf of himself/herself in the field of battle. The subjugated self-consciousness has now the additional task of relieving itself from the bonds of subordination, as long as within these bonds the deliverance from immediate individuality in general, due to the remaining immediate individuality of the master, is impossible to be accomplished in full. At the same time, the liberating activity of the subordinate has an exemplary effect on the master, with respect to his/her own release from immediacy. For although the master achieved the one-off affirmation of his/her freedom by risking his/her life to the fullest during the battle, his/her victory was accompanied by a gradual forgetfulness of the process of recognition, concerning its specific issues and stakes. As a result, he/she has returned to the idle complacency of immediately given subjectivity, placing on the bondsman's side the task of releasing freedom from given particularity. Through the progress of the bondsman towards freedom, however, the freedom of the master is also recovered. On the one hand, this is because the participation of both in one, albeit asymmetric, relationship of cooperation for the ensuring of livelihood, tends to highlight their common destination as free self-consciousnesses; and on the other hand, because the direct experience of the progressive emancipation of the bondsman on the part of the master acquaints the master with the presuppositions of his/her own emancipation.

\section{The Dawn of Rational Intersubjectivity}

The rationally regulated action of the subjugated self-consciousness to the processing of the natural material therefore has as a consequence its own mediated reformation. In this process, Hegel discovers the "beginning of wisdom" (Anfang der Weisheit). Just the beginning, however, as the terminal point of this process is located in the master's decision to liberate the bondsman, so as to be in the position to face in the otherness the exemplification of his/her own free- 
dom. With this development, we seem to have simply returned to the starting status quo, in which self-consciousness is divided into two independent parts. But it was precisely this contradiction that triggered the dialectic of recognition. Therefore, the question is; what is the distinctive mark of the current network of determination, which urges Hegel to equate it to the acquisition of wisdom?

The answer to this question is as follows: before the battle of recognition each self-consciousness intuited in the immediate independence of the other at one moment the relationship of identity and at the other moment the relationship of difference with itself. It was therefore not possible to both unite these relations, without affecting their difference, or to separate them, without affecting their unity. In short, it was impossible to conceive them in combination as a single differential whole of determination. Both self-consciousnesses held an abstract, finite, consciousness-defined view of their relationship, thus both were afflicted by division and one-sidedness in the core of their existence. At the end of the recognition process, however, a determinate structure is established on the horizon of which the independence of the other, though stable and permanent, is not threatening one's own independence, nor bringing about one's internal division. And this is because the independence of the other does not consist in his/her immediate particularity, as in the beginning of the battle of recognition. Instead, by means of the spontaneous activity of each self-consciousness immediate particularity is precluded from being the universal normative factor of the total circle of determination in the current juncture. In other words, the particular presuppositions of freedom are invalidated by themselves, insomuch as they are regarded as obstacles to the manifestation of its unconditional nature. As a consequence, although the above manifestation leads to the doubling of self-consciousness, this doubling can now be conceived as presuppositionless.

Owing to this presuppositionless doubling into two distinct self-consciousnesses, self-consciousness is revealed as a concrete universal, precisely for the reason that its particularization ceases to be deemed as an immediately given reality. On the contrary, it is enclosed in the circle of its self-actualization, functioning as the vehicle of its self-activated individualization. Particularization is no longer understood as the expression of a disruptive heteronomy but as the specific product of free universal self-determination. Indeed, the individual independence of each self-consciousness may be preserved intact and at the same time liberated from immediate subjectivity, which would make the fact of their relationship an externally imposed necessity. Thus the reciprocity of the mutually recognized self-consciousnesses opens up for them the field to exercise their objective freedom, provided that the concept of freedom consists in the spontaneous act of differentiation for the sake of self-determination. The unconditional self-determination is performed only within the consubstantiality of the autonomous self-consciousnesses, who, having shaken off every attachment to their natural differences, can now interactively determine themselves under the perspective of a commonly recognized freedom.

The Hegelian conviction that "this freedom of one in the other unifies people 
in an internal manner, while need and necessity aggregate them only externally" ${ }^{\prime 4}$ (Hegel, 2007), is explained by the fact that in need and necessity the specific character of each self-consciousness is perceived as given and not as the product of its autonomous self-determination. In case of need, the given particular individualities can be reciprocally connected to one degree or another only in a mechanical way and this connection, as it becomes clear, is unable to ascribe an additional substantial character to them and even less to give an essential dimension to their freedom, to the extent that the latter is limited to the uninhibited satisfaction of immediate desires imposed by natural necessity and accidentality. In contrast, mutual recognition renders the relation of spiritual beings a derivative of their self-determination, insomuch as is defines the locus for the manifestation of true autonomy, i.e. the autonomy that is not accounted for as having a ready-made nature before it performs the determination of its nature by itself.

The liberation from the oppression of immediate, natural individuality, as well as that from the external master, elevates spirit to the realm of reason, as long as the concept of reason denotes the emancipation from the particular perspectives and the ascent to the universality of the self-constituted intellect. The rational liberation coincides with the sublation of the consciousness-defined differentiality, which remained to overdetermine the relationship of self-consciousnesses, to the extent that each one was intuiting its freedom into the other under the guise of a foreign objectivity. In this emergence of rational autonomy Hegel acknowledges the quintessence of any spiritual interpersonal bond, such as family or state, but also the birthplace of all moral virtues such as love, friendship, honor etc. These relationships, insomuch as they dissolve the unbridgeable consciousness-defined separation of subject and object, bear the seal of the speculative reason and as Hegel states, "... if one supposes that the speculative (Spekulativ) is something remote and inconceivable, one need only consider the content of this relationship to convince oneself of the groundlessness of this opinion"15 (Hegel, 2007).

\section{Conflicts of Interest}

The author declares no conflicts of interest regarding the publication of this paper.

\section{References}

Bowman, B. (2013). Hegel and the Metaphysics of Absolute Negativity. New York: Cambridge University Press. https://doi.org/10.1017/CBO9781139520201

Burbidge, J. (1981). On Hegel's Logic (pp. 61-83). Atlantic Highlands, US: Humanities Press.

Burbidge, J. W. (2007). Hegel's Systematic Contigency (pp. 91-92). New York: Palgrave Macmillan. https://doi.org/10.1057/9780230590366

Fichte, J. G. (2000). Foundations of Natural Right (pp. 29-79). New York: Cambridge

${ }^{14}$ G. W. F. Hegel, Philosophy of Mind (New York: Oxford University Press, 2007), 158 (\$431, Zusatz).

${ }^{15}$ G. W. F. Hegel, Philosophy of Mind (New York: Oxford University Press, 2007), 163 (\$436, Zusatz). 
University Press.

Hegel, G. W. F. (2007). Philosophy of Mind (pp. 3-215). New York: Oxford University Press.

Hegel, G. W. F. (2010). The Science of Logic (pp. 530-546). New York: Cambridge University Press.

Houlgate, S. (2006). The Opening of Hegel's Logic (pp. 32-54). West Lafayette, Indiana: Purdue University Press.

Peperzak, A. (2001). Modern Freedom: Hegel's Legal, Moral and Political Philosophy (p. 141). Dordrecht, The Netherlands: Kluwer Academic Publishers. https://doi.org/10.1007/978-94-010-0856-3

Rockmore, T. (1986). Hegel's Circular Epistemology (pp. 1-110). US: Indiana University Press.

Sparby, T. (2015). Hegel's Conception of the Determinate Negation (pp. 314-340). Leiden, The Netherlands: Brill. https://doi.org/10.1163/9789004284616

Winfield, R. D. (2011). The Living Mind. Plymouth, UK: The Rowman \& Littlefield Publishers.

Winfield, R. D. (2012). Hegel's Science of Logic (pp. 345-357). Plymouth, UK: Rowman \& Littlefield Publishers. 